Available online on 15.5.2018 at http://ujpr.org
Universal Journal of Pharmaceutical Research
An International Peer Reviewed Journal
Open access to Pharmaceutical research

\title{
GC-MS ANALYSIS OF FIXED OILS OF NIGELLA SATIVA SEEDS Sania Feroz* ${ }^{\circ}$, Ghias Uddin \\ Institute of Chemical Sciences, University of Peshawar, K.P.K Peshawar-25120, Pakistan.
}

\section{ABSTRACT}

Objective: Gas chromatography-Mass spectrometry (GC-MS) is an analytical method that combines the features of gas-liquid chromatography and mass spectrometry to identify different substances within a test sample. Applications of GC-MS include drug detection, fire investigation, environmental analysis, explosives investigation, and identification of unknown samples.

Methods: The present study also relies on use of GC-MS for detection and interpretation of compounds present in N. sativa oil samples. Fixed oil was obtained through column chromatography of ethyl acetate fraction. The oil samples were subjected to GCMS analysis which showed 5, 18, 12 and 20 compounds in four fixed oil samples respectively.

Results: The major components were linoleic acid, methyl ester (35.5\%), oleic acid, methyl ester (15.007\%), palmitic acid, methyl ester $(8.208 \%)$.

Conclusion: Study concludes that in fixed oils, linoleic acid constitutes the major portion while oleic acid and palmitic acid also contributes in small quantity.

Keywords: Column chromatography, fixed oil, GC-MS, Nigella sativa.

Article Info: Received 2 March 2018; Revised 12 April; Accepted 1 May, Available online 15 May 2018

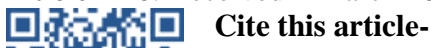

Feroz S, Uddin G. GC-MS analysis of fixed oils of Nigella sativa seeds. Universal Journal of Pharmaceutical Research 2018; 3(2): 36-40.

DOI: https://doi.org/10.22270/ujpr.v3i2.139

\section{Address for Correspondence}

Sania Feroz, Institute of Chemical Sciences, University of Peshawar, K.P.K Peshawar-25120, Pakistan, E-mail: muskroz1@gmail.com

\section{INTRODUCTION}

Plant-derived substances are now being widely used as medicines as these have recently become of great interest owing to their versatile applications. Medicinal plants are the richest natural bio-resource of drugs of traditional systems of medicine. With the advancement in research medicinal plants are considered a source of modern medicines, nutraceuticals, food supplements, folk medicines, pharmaceutical intermediates and chemical entities for synthetic drugs ${ }^{1}$. Extraction (as the term is pharmaceutically used) is the separation of medicinally active portions of plant tissues using selective solvents through standard procedures. Oilseeds are important sources of oils of nutritional, industrial and pharmaceutical importance. Nonconventional oilseeds are being considered because their constituents have unique chemical properties and may augment the supply of edible oils ${ }^{2}$. The study of oilseeds for their minor constituents is useful in order to use both oil and minor constituents effectively.

Nigella sativa, which belongs to the family Ranunculaceae, commonly grows in Eastern Europe, the Middle East, and Western $\mathrm{Asia}^{3}$. It is a small shrub with tapering green leaves and bearing white and purplish flowers. Its ripe fruit contains tiny black seeds, commonly known as black seeds in English ${ }^{4}$. Seeds of $N$. sativa are frequently used in folk medicine in the Middle East and some Asian countries for the promotion of good health. Seeds are used for the treatment of various diseases including fever, the common cold, headache, asthma, rheumatic diseases, and microbial infections and to expel worms from the intestines as well as cancer. In addition, it is used as a flavoring additive to bread and pickles. ${ }^{5}$. The seeds contain a yellowish volatile oil, a fixed oil, proteins, amino acids, reducing sugars, mucilage, alkaloids, organic acids, tannins, resins, toxic glycoside, glycosidal saponins, crude fiber, minerals, and vitamins ${ }^{6}$. The aim of the present study was to find the composition of fixed and volatile oils obtained from ethyl acetate fraction.

\section{MATERIALS AND METHODS}

Plant Material: The seeds of $N$. sativa were purchased from a local spice market of Peshawar, KPK Pakistan.

Plant Identification: The purchase seeds of $N$. sativa were identified by a botanist, Prof. Dr. Abdur Rashid, in Department of Botany, University of Peshawar, KPK Pakistan. 
Extraction and fractionation: The seeds were grinded in a rotary mill and crude extract was obtained. This extract was fractionated with polar and non polar solvents which were methanol, ethyl acetate, chloroform and $n$-hexane respectively. Then, each fractionated sample was concentrated in rotary evaporator and solvent was removed to obtain concentrated extract ${ }^{7}$.

GC-MS analysis of fixed oil: A Shimadzu gas chromatograph, hyphenated to a QP2010 plus (Tokyo, Japan) mass spectrometer, outfitted with an autoinjector (AOC-20i) and auto sampler (AOC-20S) was used. The carrier gas used was Helium and a capillary column TRB-FFAP of specification: length; 30m, thickness; $0.250 \mu \mathrm{m}$, i.d.; $0.35 \mathrm{~mm}$ and treated with polyethylene glycol was used for all chromatographic separations. Other GC-MS parameters are: pressure: $100 \mathrm{KPa}$, temperature: $240^{\circ} \mathrm{C}$, solvent cut time; $1.6 \mathrm{~min}$. $1 \mu 1$ of standard and sample were injected into the column of GC. The injector operatory mode was a split mode, with a split ratio of $1: 50$, and $240^{\circ} \mathrm{C}$ as an injection temperature. Initially the column temperature was $50^{\circ} \mathrm{C}$ and was changed at the rate of $15^{\circ} \mathrm{C}$ for each minute and raised to $150^{\circ} \mathrm{C}$. After $150^{\circ} \mathrm{C}$, the rising rate of temperature was $2.5^{\circ} \mathrm{C}$ per minute and was raised to $175^{\circ} \mathrm{C}$ and was maintained for 5 minutes. Then, the rising rate of temperature was $2.5^{\circ} \mathrm{C}$ per minute at which the temperature was to $220^{\circ} \mathrm{C}^{8}$.

MS scanning was executed from $\mathrm{m} / \mathrm{z} 85$ to $\mathrm{m} / \mathrm{z} 380$. GC-MS solutions software, provided by the supplier was used for the system control and acquiring the data. Compounds identification was carried out by the comparison of the relative retention times of the components and obtained mass spectra with standard mass spectra (from the NIST library, NIST 05).

\section{RESULTS AND DISCUSSION}

Four samples of fixed oils were obtained and were subjected to GC-MS analysis. GC-MS analysis confirmed the presence of various compounds in fixed oils in different ratio. GC-MS analysis of fixed oils is illustrated in Figure 1, 2, 3 and 4 respectively. The graphs are also illustrated in tabular forms in Table 1, Table 2, Table 3 and Table 4 respectively.

Table 1: GC-MS analysis of $N$. sativa fixed oil (sample 1).

\begin{tabular}{ccccc}
\hline S. N. & Name & R. Time & Area & Con. (\%) \\
\hline 1. & C12:0; Lauric acid, methyl ester & 8.085 & 4794 & 0.005 \\
2. & C14:0, Myristic acid, methyl ester & 10.175 & 7114 & 0.007 \\
3. & C16:0, Palmitic acid, methyl ester & 13.410 & 43880 & 0.042 \\
4. & C18:0, Stearic acid, methyl ester & 17.851 & 25010 & 0.024 \\
5. & C18:1c, Oleic acid, methyl ester & 18.262 & 8149 & 0.028 \\
\hline
\end{tabular}

Table 2: GC-MS analysis of $N$. sativa fixed oil (sample 2).

\begin{tabular}{clccc}
\hline S. N. & \multicolumn{1}{c}{ Name } & R. Time & Area & Conc. (\%) \\
\hline 1. & C6:0; Hexanoic acid, methyl ester & 2.944 & 19619 & 0.058 \\
2. & C8:0; Caprylic acid, methyl ester & 4.743 & 3433 & 0.006 \\
3. & C10:0; Capric acid, methyl ester & 6.503 & 12385 & 0.017 \\
4. & C11:0; Undecanoic acid, methyl ester & 7.290 & 1456 & 0.002 \\
5. & C12:0; Lauric acid, methyl ester & 8.084 & 21023 & 0.026 \\
6. & C13:0; Tridecanoic acid, methyl ester & 9.010 & 2152 & 0.003 \\
7. & C14:0; Myristic acid, methyl ester & 10.176 & 116414 & 0.136 \\
8. & C15:0; Pentadecanoic acid, methyl ester & 11.636 & 15267 & 0.018 \\
9. & C16:0; Palmitic acid, methyl ester & 13.420 & 2086913 & 2.380 \\
10. & C17:0; Margaric acid, methyl ester & 15.499 & 15200 & 0.018 \\
11. & C18:0; Stearic acid, methyl ester & 17.859 & 517160 & 0.599 \\
12. & C18:1c; Oleic acid, methyl ester & 18.288 & 900188 & 3.764 \\
13. & C18:1n9t; Elaidic acid, methyl ester & 18.471 & 35271 & 0.202 \\
14. & C18:2c; Linoleic acid, methyl ester & 19.572 & 2739870 & 10.092 \\
15. & C18:2t; Octadecadienoic acid, methyl ester & 19.733 & 15718 & 0.056 \\
16. & C18:3n3; Linolenic acid, methyl ester & 21.669 & 11169 & 0.044 \\
17. & C20:0; Arachidic acid, methyl ester & 24.618 & 20659 & 0.025 \\
18. & C20:2c; 11,14-Eicosadienoic acid, methyl ester & 26.942 & 90808 & 0.319 \\
\hline
\end{tabular}

Table 3: GC-MS analysis of $N$. sativa fixed oil (sample 3).

\begin{tabular}{ccccc}
\hline S. N. & Name & R. Time & Area & Conc. $(\boldsymbol{\%})$ \\
\hline 1. & C6:0; Hexanoic acid, methyl ester & 2.945 & 2382 & 0.006 \\
2. & C12:0; Lauric acid, methyl ester & 8.084 & 5334 & 0.006 \\
3. & C14:0; Myristic acid, methyl ester & 10.176 & 20552 & 0.020 \\
4. & C15:0; Pentadecanoic acid, methyl ester & 11.637 & 6708 & 0.007 \\
5. & C15:1; Pentadecenoic acid, methyl ester & 12.012 & 5410 & 0.025 \\
6. & C16:0; Palmitic acid, methyl ester & 13.413 & 201325 & 0.195 \\
7. & C16:1; Palmitoleic acid, methyl ester & 13.883 & 9593 & 0.046 \\
8. & C17:0; Margaric acid, methyl ester & 15.504 & 6276 & 0.006 \\
9. & C18:0; Stearic acid, methyl ester & 17.853 & 60741 & 0.060 \\
10. & C18:1c; Oleic acid, methyl ester & 18.268 & 59189 & 0.211 \\
11. & C18:1n9t; Elaidic acid, methyl ester & 18.469 & 6962 & 0.034 \\
12. & C18:2c; Linoleic acid, methyl ester & 19.533 & 70260 & 0.220 \\
\hline
\end{tabular}


Current study has reported the chemical composition of fixed oils of $N$. sativa. GC-MS analysis of oils confirmed the presence of various compounds in them. Four samples of fixed oils were obtained and subjected to GC-MS analysis. In the first sample, all methyl esters were present in very small quantity (Table 1). GC-MS analysis of second sample showed that linoleic acid was the major component which was $10 \%$ followed by oleic acid and palmitic acid which are
$3.76 \%$ and $2.38 \%$ respectively while other compounds were in small quantity (Table 2). Analysis of third sample showed that various methyl esters were present but in small amounts (Table 3). GC-MS analysis of fourth sample explored that linoleic acid (35.55\%) was the major component while oleic acid (15.007\%), palmitic acid $(8.20 \%)$ and stearic acid $(1.877 \%)$ were also present. Many other components were present in minute quantities (Table 4).

Table 4: GC-MS analysis of $N$. sativa fixed oil (sample 4).

\begin{tabular}{|c|c|c|c|c|}
\hline S. $\mathbf{N}$. & Name & R. Time & Area & Conc. (\%) \\
\hline 1. & C6:0; Hexanoic acid, methyl ester & 2.945 & 12976 & 0.039 \\
\hline 2. & C8:0; Caprylic acid, methyl ester & 40744 & 1355 & 0.002 \\
\hline 3. & C12:0; Lauric acid, methyl ester & 8.085 & 5679 & 0.007 \\
\hline 4. & C13:0; Tridecanoic acid, methyl ester & 9.187 & 1808 & 0.002 \\
\hline 5. & C14:0; Myristic acid, methyl ester & 10.180 & 109863 & 0.128 \\
\hline 6. & C15:0; Pentadecanoic acid, methyl ester & 11.641 & 20937 & 0.025 \\
\hline 7. & C15:1; Pentadecenoic acid, methyl ester & 12.017 & 11790 & 0.065 \\
\hline 8. & C16:0; Palmitic acid, methyl ester & 13.448 & 7199712 & 8.208 \\
\hline 9. & C16:1; Palmitoleic acid, methyl ester & 13.895 & 29472 & 0.165 \\
\hline 10. & C17:0; Margaric acid, methyl ester & 15.513 & 31426 & 0.038 \\
\hline 11. & C17:1; Heptadecenoic acid, methyl ester & 15.956 & 2716 & 0.015 \\
\hline 12. & C18:0; Stearic acid, methyl ester & 17.897 & 1621340 & 1.877 \\
\hline 13. & C18:1c; Oleic acid, methyl ester & 18.354 & 3590155 & 15.007 \\
\hline 14. & C18:1n9t; Elaidic acid, methyl ester & 18.506 & 172499 & 0.987 \\
\hline 15. & C18:2c; Linoleic acid, methyl ester & 19.680 & 9657037 & 35.555 \\
\hline 16. & C18:2t; Octadecadienoic acid, methyl ester & 19.742 & 99458 & 0.353 \\
\hline 17. & C18:3n3; Linolenic acid, methyl ester & 21.689 & 32240 & 0.126 \\
\hline 18. & C20:0; arachidic acid, methyl ester & 24.637 & 70834 & 0.086 \\
\hline 19. & C20:1c; 11-Eicosenoic acid, methyl ester & 25.215 & 55869 & 0.245 \\
\hline 20. & C20:2c; 11,14-Eicosadienoic acid, methyl ester & 26.970 & 432857 & 1.518 \\
\hline
\end{tabular}

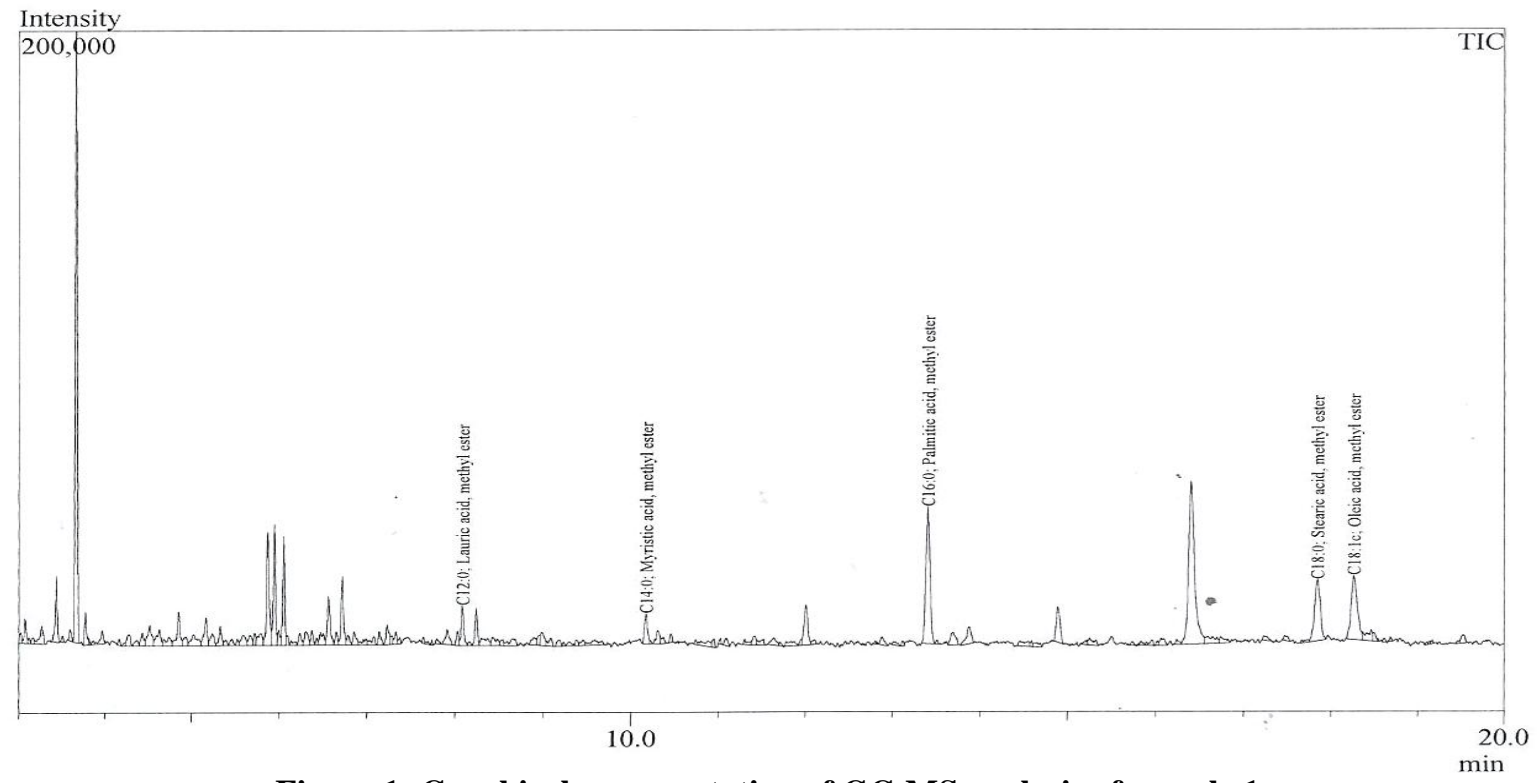

Figure 1: Graphical representation of GC-MS analysis of sample 1. 


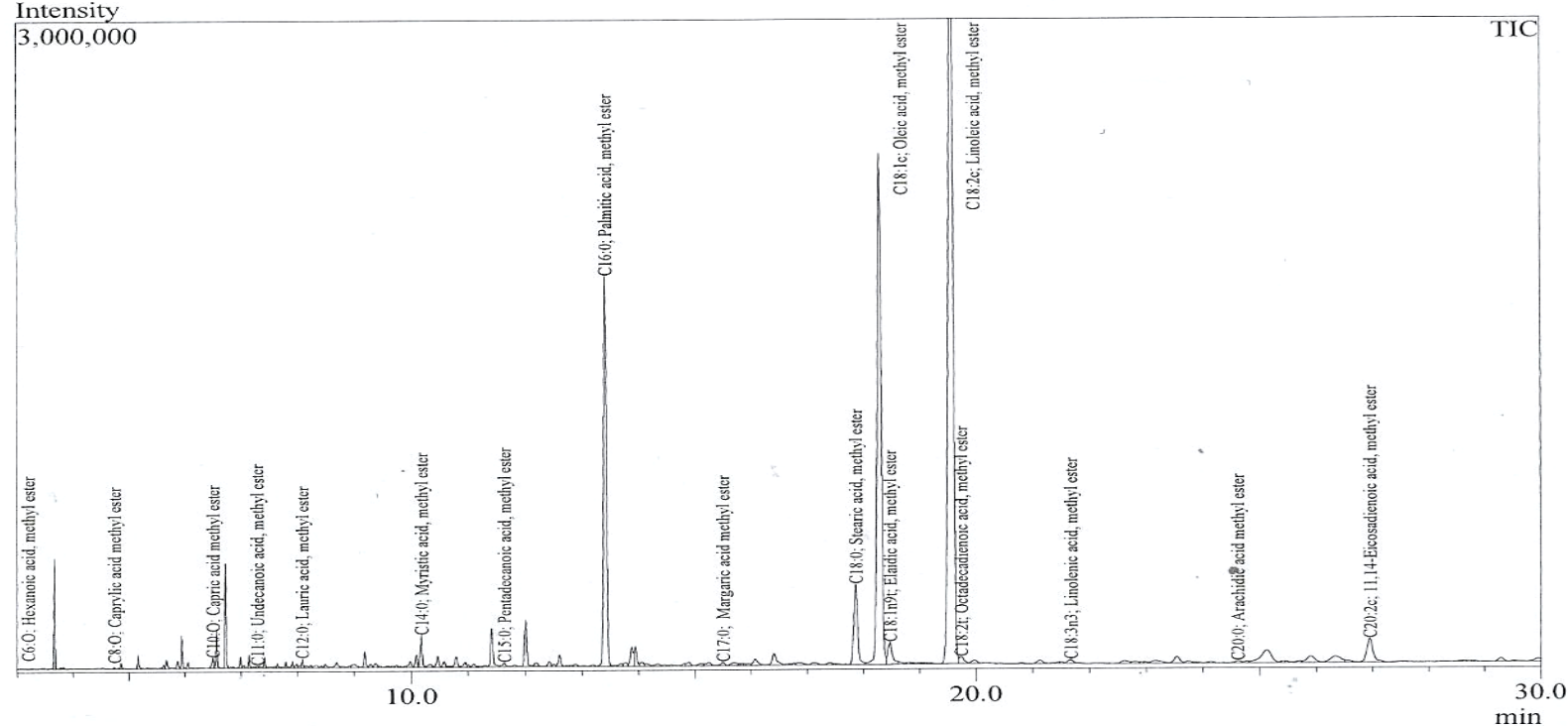

Figure 2: Graphical representation of GC-MS analysis of sample.

Intensity 400,000

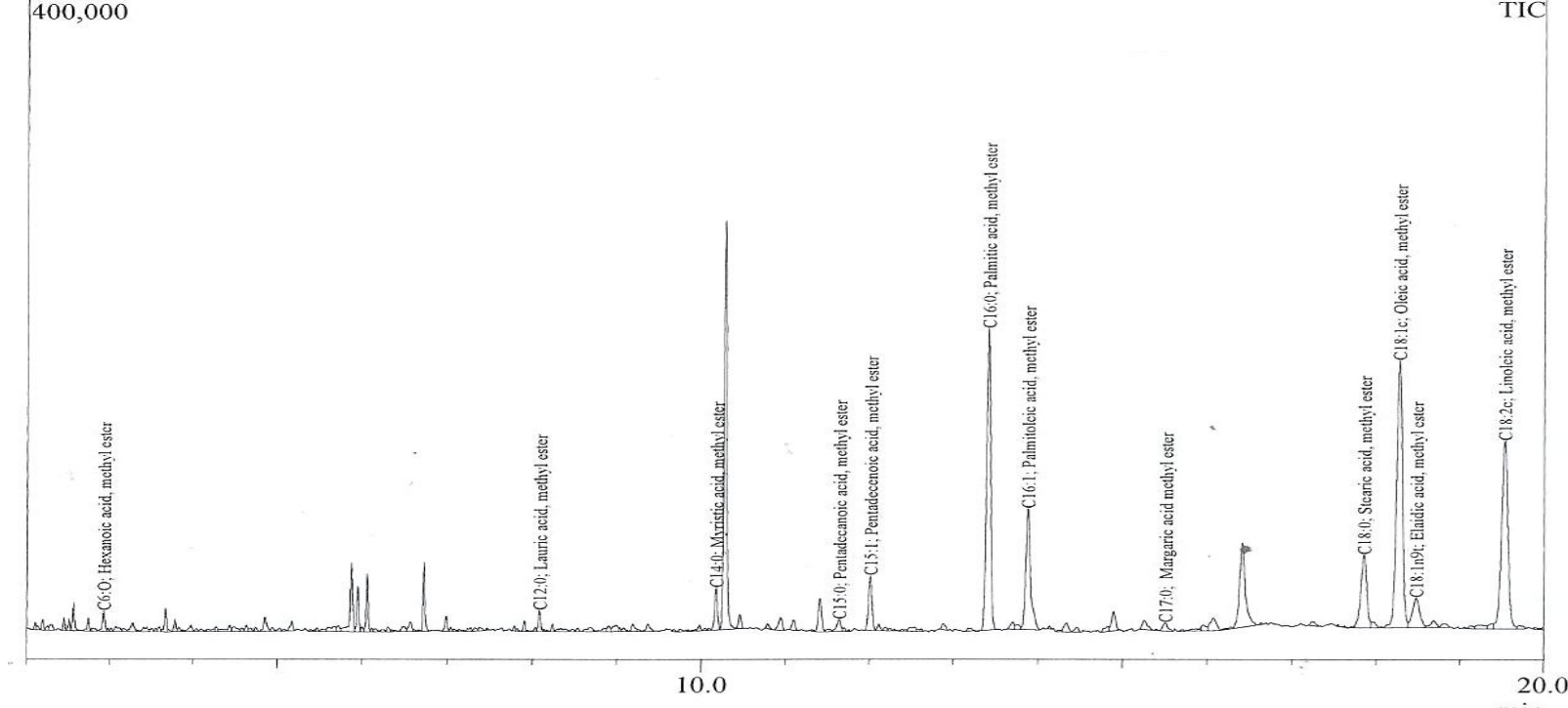

Figure 3: Graphical representation of GC-MS analysis of sample 3.

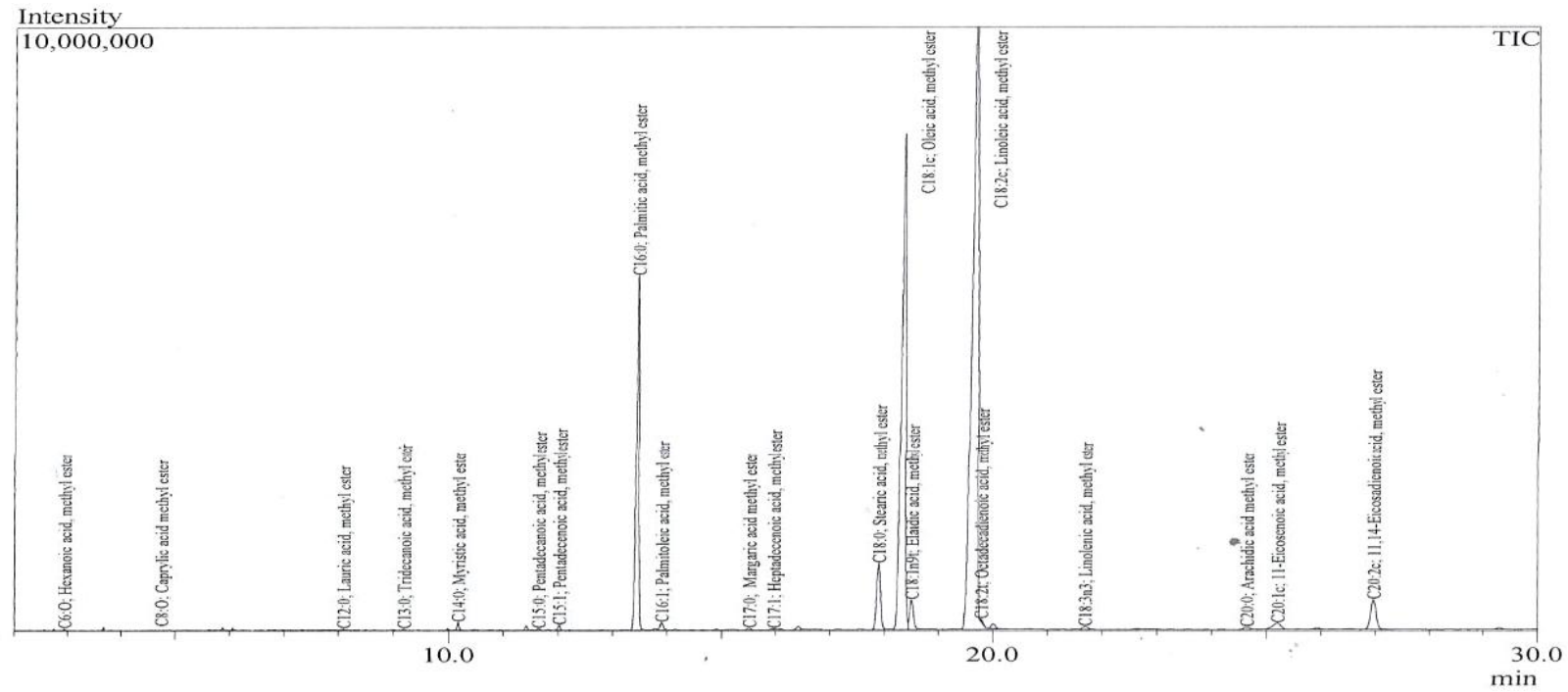

Figure 4: Graphical representation of GC-MS analysis of sample 4. 


\section{CONCLUSION}

Study concludes that in fixed oils, linoleic acid constitutes the major portion while oleic acid and palmitic acid also contributes in small quantity. Many other components are also present in very minute amount.

\section{AUTHOR'S CONTRIBUTION}

The manuscript was carried out, written, and approved in collaboration with all authors.

\section{ACKNOWLEDGEMENTS}

The authors extend their thanks and appreciation to the National Center for Public Health to provide necessary facilities for this work.

\section{CONFLICT OF INTEREST}

No conflict of interest associated with this work.

\section{REFERENCES}

1. Ncube NS, Afolayan AJ, Okoh AI. Assessment techniques of antimicrobial properties of natural compounds of plant origin: current methods and future trends. Afr J Biotechnol 2008; 7: 1797-1806. https://doi.org/10.1186/1472-6882-6-11
2. Ramadan MF, Morsel JT. Analysis of glycolipids from black cumin (Nigella sativa L.), coriander (Coriandrum sativum L.) and niger (Guizotia abyssinica Cass.) oil seeds. Food Chem 2003; 80:197-204. https://doi.org/10.1016/S0308-8146(02)00254-6

3. Ali BH, Blunden G. Pharmacological and toxicological properties of Nigella sativa. Phytother Res 2003; 17: 299305. https://doi.org/10.1002/ptr.1309

4. El-Din K, El-Tahir H, Bakeet DM. The Black Seed Nigella sativa Linnaeus - A mine for multi cures: A plea for urgent clinical evaluation of its volatile oil. J Taibah Univ Med. Sci 2006; 1: 1-19.https://doi.org/10.1016/S1658-3612(06)70003-8

5. Randhawa MA, Alghamdi MS. Anticancer Activity of Nigella sativa (Black Seed). Am J Chin Med 2011; 39: 10751091.https://doi.org/10.1142/S0192415X1100941X

6. Ramadan MF. Nutritional value, functional properties and nutraceuticals applications of black cumin (Nigella sativa L.): an overview. Int J Food Sci Tech 2007; 42: 1208-1218. https://doi.org/10.1111/j.1365-2621.2006.01417.x

7. Ullah H, Rauf A, Ullah Z, Anwar M, Shah AUH, Uddin G, Ayub K. Density functional theory and phytochemical study of Pistagremic acid. Spectrochim. Acta A: Mol. Biomol. Spectrosc 2014; 118: 210-214.

https://doi.org/10.1016/j.saa.2013.08.099

8. Edrees WHA, Abdullah QYAM, AL-Kaf AG, Naji KM. A review on comparative study between the physicochemical and biological processes for paracetamol degradation. Universal J Pharm Res 2017; 2(2): 32-41. http://doi.org/10.22270/ujpr.v2i2.RW4 